\title{
Earthquake Education Through the Use of Documentary Movies
}

\author{
Batmanathan Navakanesh ${ }^{1}$, Afroz Ahmad Shah ${ }^{2 *}$ and M. V. Prasanna ${ }^{1}$ \\ ${ }^{1}$ Department of Applied Geology, Faculty of Engineering and Science, Curtin University Malaysia, Miri, Malaysia, \\ ${ }^{2}$ Department of Physical and Geological Sciences, University of Brunei Darussalam, Bandar Seri Begawan, Brunei
}

\section{OPEN ACCESS}

Edited by:

Jonathan D. Paul,

Imperial College London,

United Kingdom

Reviewed by:

Wen-Tzong Liang,

Academia Sinica, Taiwan

Yasamin O. Izadkhah,

International Institute of Earthquake

Engineering and Seismology, Iran

*Correspondence:

Afroz Ahmad Shah

afroz.shah@ubd.edu.bn;

afroz.shah@gmail.com

Specialty section:

This article was submitted to Geohazards and Georisks,

a section of the journal

Frontiers in Earth Science

Received: 01 October 2018

Accepted: 20 February 2019

Published: 19 March 2019

Citation:

Navakanesh B, Shah AA and Prasanna MV (2019) Earthquake

Education Through the Use

of Documentary Movies.

Front. Earth Sci. 7:42.

doi: 10.3389/feart.2019.00042
Unscientific, false, inaccurate and/or exaggerated reporting about anything in media or other platforms is a serious concern that needs a solution. This is particularly important when reporting about disasters (e.g., earthquakes). The lack of authentic scientific input into about science news reporting may can lead to news disasters, which may can prove to be much more critical and dangerous than say -earthquake disasters. Therefore, this paper explores such a this problem in a portion of NW Borneo and offers solution to improve the existing norms on the earthquake science, education and awareness programs in SE Asia. The explored field location is Sabah, Malaysia, which is targeted to map the level of earthquake science education and awareness of local people, and to examine the co-seismic deformation associated with the 5th June, 2015 earthquake. This event has surprised the local communities because the region is geographically located away from the active tectonic plate boundaries, and has traditionally been considered a low earthquake risk region. This is in contrast to the existence of high earthquake hazard and risk regions in the neighboring Indonesia and the Philippines. Therefore, not surprisingly, the residents of Borneo where puzzled, surprised, and worried when a medium magnitude earthquake occurred and caused significant loss of life and property. The lack of scientific education on the causes, and remedies of earthquake hazards in most of the South and Southeast Asian regions is a reality, which needs a proper solution. Therefore, through this work a small initiative has been started in Sabah, Malaysia where stories from the earthquake victims were recorded after the devastation caused by the June 2015 earthquake. Their real time experiences were blended with the updated scientific data on the occurrence of earthquakes in Borneo, which are mostly gathered from previously published works and the work presented here. The entire work is converted into a small documentary movie that highlights the causes of earthquakes and how it impacts human life.

Keywords: earthquake, Sabah, NW Borneo, education, hazard

\section{INTRODUCTION}

Science education historians have suggested that one of the prime facets of scientific literacy is to understand and examine reporting and discussion on science that appear in the popular media (DeBoer, 2000). And with the advancement of technology to communicate science it has become increasingly difficult to differentiate facts from fiction (Barnett et al., 2006). This is particularly 
true in fictional cinema and television on science that has blurred the distinction between fact and fiction (Frank, 2003). These concerns were also raised by National Science Foundation (2000) by arguing that visual media has corroded the critical thinking of public at large because it lacks credibility, authenticity, and honesty on scientific reporting. It is therefore imperative to communicate authentic science to public, which can be achieved if scientists are actively involved in such endeavors. And since most of the people use various types of technical gadgets to learn about science therefore it will be easy to feed scientifically valid information through the use of modern technological tools. Below we demonstrate through our work in Malaysia and Brunei that valid and updated earthquake science education and awareness campaign is needed to fill the gap that is evident in the region. The earthquake hazards are a great concern to most of South and Southeast Asia countries (Figures 1, 2), which makes communication authentic science to people an urgency.

Our concern about the earthquake hazards and scientific awareness in SE Asia with a special focus on Malaysia started in 2010 with a small contribution published in 2015 (Shah, 2015) where a comprehensive methodology and planning to map all of the seismogenic structures in Malaysia is highlighted. The equally important component of the work was to translate earthquake science education into action on ground via education and awareness campaign. Therefore, keeping in view the importance of earthquake science in Malaysia the second authors of this contribution applied for a research grant in 2013-2014 but unfortunately the grant was rejected by the review committee which argued that since there is no earthquake threat in Malaysia therefore it was not important and necessary to fund such a research proposal. This was $\sim 2$ years before the June 2015 quake that caused significant damage to the life and property (Shah, 2015; Shah et al., 2018c) in Sabah (Figure 1). This motivated us further to raise awareness about the science of earthquake hazards in the region, which has somehow remained elusive even from the responsible scientific community. The Sabah event caused widespread public outrage, and forced researchers to rethink about the traditional interpretation of the earthquake hazards in Borneo (Shah, 2015; Wang et al., 2017; Shah et al., 2018b). And the realization to have a competent earthquake education and outreach program mainly comes from the field interaction with locals in parts of Malaysia and Brunei. The local Malaysian students (undergraduates and graduates) are asked about the earthquake hazards in the country and they have shown complete lack of knowledge about the fault system in their neighborhood, and what lies under their feet (Shah et al., 2018b). Their confident outlook of not knowing about the earthquake hazards, and the potential impact of a future earthquake is a direct outcome of the background education and information that these students are exposed to (e.g., Balendra and Li, 2008; Lam et al., 2016; Loi et al., 2018; Shah et al., 2018b). Therefore, the present work is built on the published literature about the earthquake science education and how that information percolates down in the public domain. Such works are few, because most of the scientific research is usually concerned about the science and very few on how that science is transported into the public spheres and action on ground (e.g., Sandal, 1996; Hall, 2002; Balaguru et al., 2003;
Hesse et al., 2009; Morley, 2009; Cullen, 2010; King et al., 2010a,b; Sapin et al., 2013; Shah, 2013; Mathew et al., 2016a,b; Menier et al., 2017; Tongkul, 2017; Wang et al., 2017; Shah et al., 2018c).

The present work demonstrates a small documentary project, funded by National Geographic Foundation, on the understating of occurrence and causes of earthquakes in Sabah, Malaysia. A medium magnitude earthquake struck Sabah on 5th June 2015 (UTC+8) and caused a great loss to life and property (Wang et al., 2017; Shah et al., 2018c). The earthquake challenged the popular consensus among public that Borneo is seismically stable, and that there was no need to worry about earthquake hazards in the region. This information feeds on the historical seismicity data of the region, which show the lack of occurrence of medium to large magnitude earthquakes, and that is possibly the main reason that earthquake resistant building codes are not a prerequisite for building structures in Borneo. This motivated us to generate updated information on earthquakes occurrences in the region, and communicate this vital information through a less than 10 min long documentary movie on Sabah earthquake. We are deeply encouraged by the work produced by the Earth Observatory of Singapore, which is part of Nanyang Technological University, and the only place in SE Asia where research in Earth Sciences, and particularly on disasters is translated into documentary, animation, and computer games. Some of their famous works are: Mayon: The Volcano Princess, Sudden Nature, Earth Girl and People-Coral-Mentawai. These works offer a perfect blend of science, society, and education, and this motivated us to take a small step toward working on earthquake science education via documentary movies.

\section{BRIEF TECTONIC BACKGROUND OF THE STUDY AREA}

The regional tectonic map (Figure 1) of northwest Borneo shows Sabah is enclosed within a network of active tectonic plate boundaries that include Indo-Australian, Eurasian, and Philippines Sea plates (Figure 1). The distribution and depth of earthquake hypocenters indicate a sack like clustering that surrounds NW Borneo, and it testifies the occurrence of active plate boundaries in the region. Seismicity is scarcely distributed in most of Borneo compared to the NW portions where more earthquakes are observed. And this configuration remain consistent with its location relatively far from the regional plate boundaries (e.g., Hall et al., 2008; Sapin et al., 2011; Wang et al., 2017; Shah et al., 2018c). Such observations are further supported by the lack of significant volcanic activity, coupled with relatively low, and apparently variable presentday geodetic convergence rates relative to Eurasia (Sapin et al., 2013). However, the prominent structural, and topographical expression of mountains and valleys in the region cannot be overlooked (Shah et al., 2018c). The well-developed mountain ranges are carved by channels, and various small valleys occur right in the middle of mountains which are filled with Quaternary to Recent fluvial deposits. This requires understanding. And although the earthquake distribution in NW Borneo is scarce but their occurrence needs to be understood to fully comprehend 


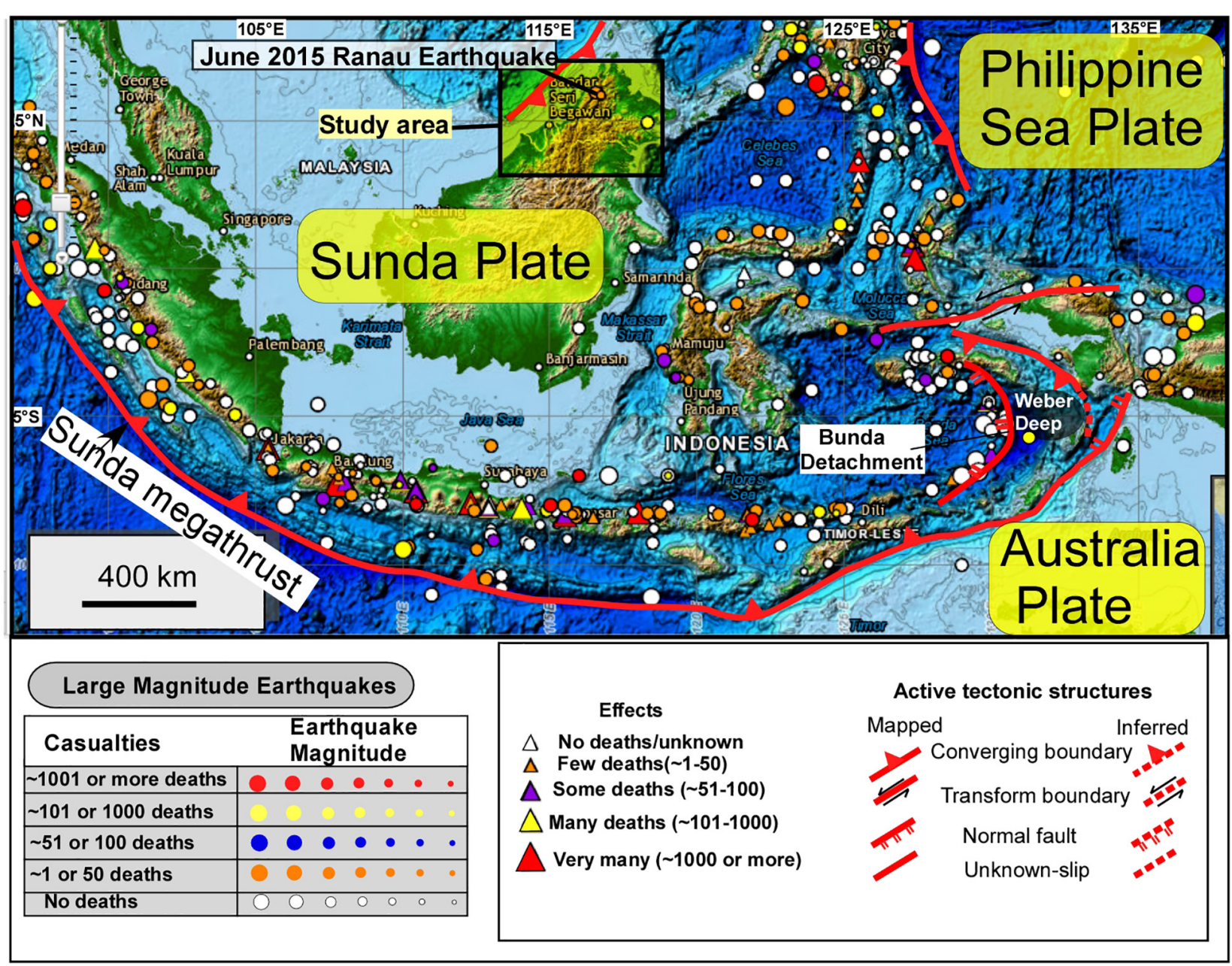

FIGURE 1 | Regional tectonic map of SE Asia (after Shah et al., 2018c) shows the distribution of lithospheric plates and the location of earthquakes, volcanoes, and some of the major active fault systems. The earthquake and plate boundary data (some boundaries are modified herein) are obtained from the National Geophysical Data Center/World Data Service (NGDCMDS): Significant Earthquake Database. National Geophysical Data Center, NOAA. doi: 10.7289/N5TD9V7K.

the earthquake geology of the region. Undoubtedly, the recent earthquake in Sabah (Figure 3) (Shah et al., 2018b) has initiated an interest and unrest in academic, research, and public spheres about the causes and concerns of earthquake occurrences in the region. Historically, the earthquake is regarded as the biggest recorded earthquake in the region, which led to an unfortunate loss of significant life and property (Wang et al., 2017; Shah et al., 2018c). And most of the casualties were of hikers who used to hike the Mount Kinabalu peak which is the highest mountain in Malaysia, and attracts a large number of hikers globally. The loss of life teaches us that even if a region is located away from the active plate boundaries, the impact of intraplate earthquake hazards cannot be overlooked (Shah et al., 2018b).

\section{METHODOLOGY}

The standard methodology adapted here uses geological field investigations as a tool to map the evidence of faulting in parts of Sabah (Figure 4). The freely available Google satellite and GeoMap App. data are used to prepare the basemap (Figures 3, 4) onto which the potential field locations are plotted. These data are aided by the Garmin GPS (Oregon 750). Figure 4 shows the location map of geological outcrops and other field sites visited during the fieldwork. Most of data are collected from the selected sites that were affected by the 2015 earthquake. The typical earthquake related investigation session with locals is shown in Table 1. Some of the interviews with locals were recorded, and before that a formal written and informed consent form was signed by each participant. Lack of funding is the only reason that stopped us to expand the sampling size, and it is anticipated that in future this void can be filled. Therefore, the limited data presented below show the importance of undertaking a large scale sampling in the region. The seismological data shown here are not relocated, and therefore there are error bars associated with both the vertical and horizontal distribution 


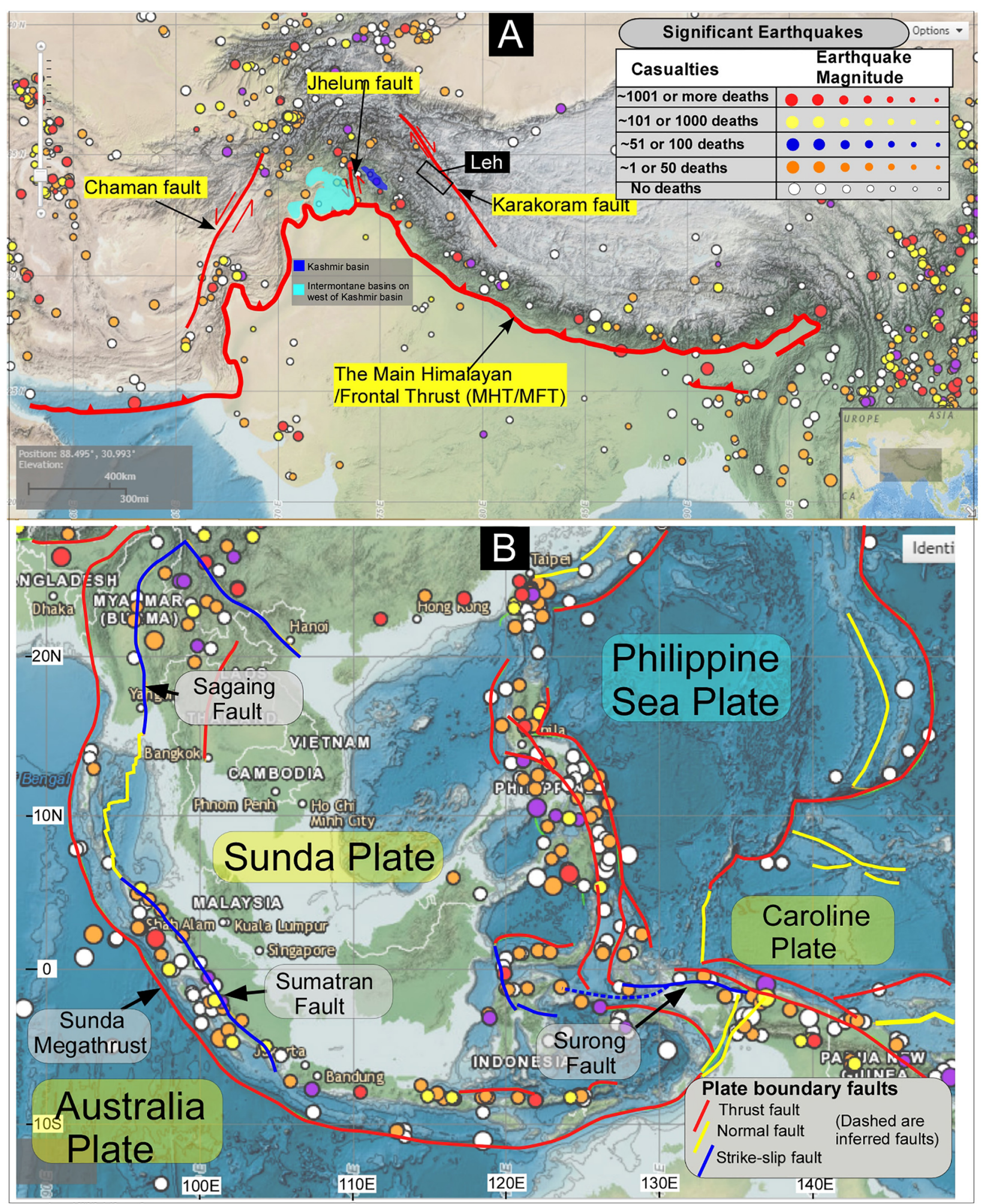

FIGURE 2 | (A) The topographic map shows some of the major faults in South (after Shah et al., 2018a) and Southeast Asia (B). The colored dots are significant earthquakes (Mw 6 and above with a depth of 0-50 km) in the region, which dates back to 2150 B.C. until present. The earthquake and plate boundary data (some boundaries are modified) are obtained from the National Geophysical Data Center/World Data Service (NGDC/WDS): Significant Earthquake Database. National Geophysical Data Center, NOAA. doi: 10.7289/N5TD9V7K. 


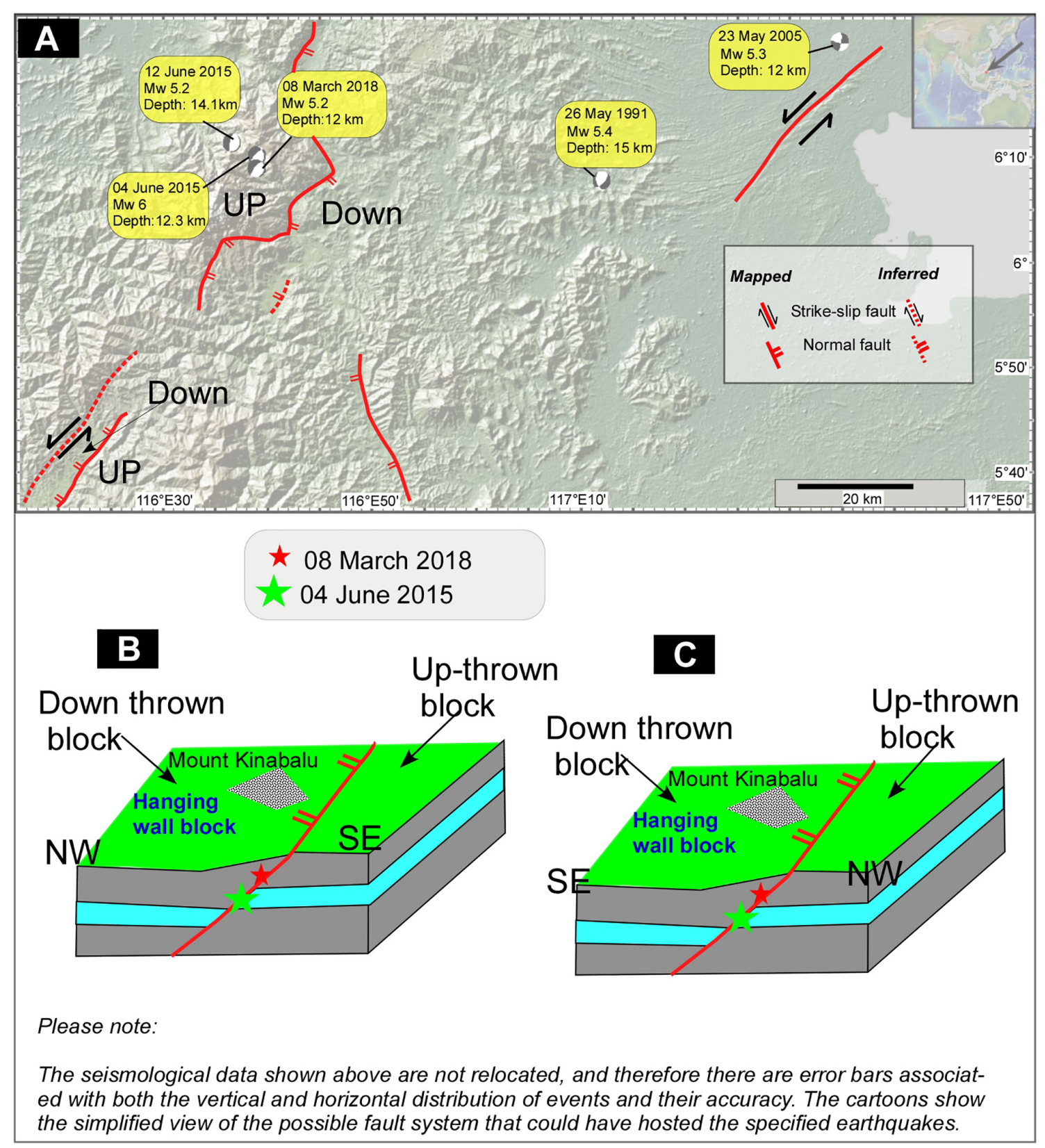

FIGURE 3 | Topographic and structural map of NW Borneo shows the locations of Centroid-Moment-Tensor solutions and the traces of active faults (A). The figure is created using the GeoMap App. software, which uses data from the Global Centroid-Moment-Tensor Project since the year 1976 until now. The most of the mapped active faults are after Shah (2015) and Shah et al. (2018b). The cartoon (B) shows the structurally most feasible fault plane on which the June 2015 and March 2018 earthquake events might have originated. The SE dipping fault plane is not fitting well with the fault parameters and the field data (C).

of events and their accuracy (e.g., Bondár et al., 2004; Bondár and McLaughlin, 2009).

\section{RESULTS AND INTERPRETATION}

\section{Fieldwork in Ranau, Sabah}

The geological field investigations were carried out in February, April and July of year 2017 with an underlying mission to map the evidence of co-seismic deformation related to the June 2015 earthquake, and to interact with locals to know about their knowledge on earthquake hazards in the region. A total of 50 geological outcrops were examined, and most of these sites expose interbedded sandstone and shale lithology of Miocene age. A series of $\sim \mathrm{NW}$ and SE dipping normal faults are mapped at a number of sites (e.g., Figure 5). These faults have vertically displaced some marker beds and the displacement varies from a few centimeters to meters (Figure 5). The normal faults 


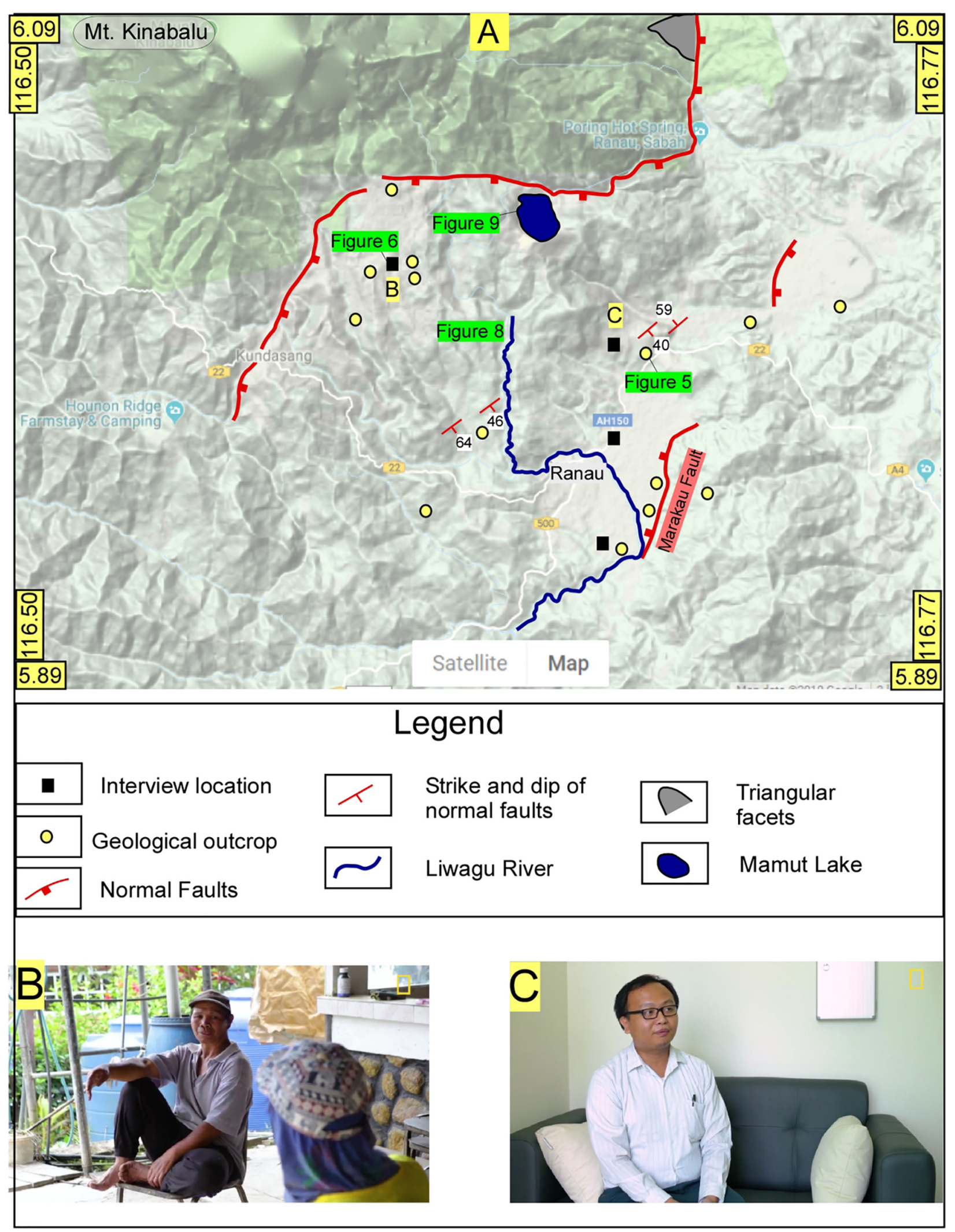

FIGURE 4 | Google terrain map shows the geological field investigation sites (A) and the location of oral interviews (B,C). Some of the active faults and geological bedrock data are also shown. 
TABLE 1 | A typical questionnaire that was used to map the earthquake damage, education and awareness during the field interaction sessions with locals in Sabah, Malaysia.

\begin{tabular}{|c|c|c|}
\hline No. & Typical questions & Typical answers \\
\hline 1 & $\begin{array}{l}\text { Briefly explain your experience during the 5th June } 2015 \text { earthquake } \\
\text { that occurred in Ranau, Sabah. }\end{array}$ & We were totally surprised and scared. \\
\hline 2 & Can you give an approximate time and duration of the main quake? & $\begin{array}{l}\text { The earthquake occurred between } 6 \text { and } 7 \text { a.m., it lasted for about } 7 \mathrm{~s} \text { in } \\
\text { Ranau, and about } 10 \mathrm{~s} \text { in Kota Kinabalu. }\end{array}$ \\
\hline 3 & Did you observe any damages due to the earthquake? & $\begin{array}{l}\text { Yes, the Liwagu lodge was closed for a week due to flooding that occurred after } \\
\text { the earthquake. The water tank had burst, and there was no electricity and } \\
\text { phone signal. Some windows were also shattered. One fishing pool moved } \\
\text { sideways and cracks developed. }\end{array}$ \\
\hline 4 & Have you felt trauma after the earthquake? & $\begin{array}{l}\text { Yes. We were traumatized because we never felt an earthquake before. It was a } \\
\text { total surprise. }\end{array}$ \\
\hline 5 & $\begin{array}{l}\text { Was such an earthquake expected in the region. Earthquakes in the } \\
\text { region? }\end{array}$ & No, we were told that Malaysia is not an earthquake prone region. \\
\hline 6 & $\begin{array}{l}\text { What is your knowledge about earthquake hazards in the Sabah } \\
\text { region? }\end{array}$ & $\begin{array}{l}\text { We know that earthquakes are not a problem for Sabah. We are safe as we } \\
\text { belong to the stable part of the Borneo Island. }\end{array}$ \\
\hline 7 & Has your perspective changed after the 2015 quake? & $\begin{array}{l}\text { It has definitely changed. We have experienced aftershocks for more than } 30 \\
\text { times since then. }\end{array}$ \\
\hline 8. & Do you know what to do before, during and after an earthquake? & No, we are not aware about it. \\
\hline 9. & $\begin{array}{l}\text { Do you think the government should provide resources for earthquake } \\
\text { education? }\end{array}$ & $\begin{array}{l}\text { Yes, we want to know why earthquakes occur, and what will happen in future, } \\
\text { and how to live with such hazards. }\end{array}$ \\
\hline
\end{tabular}

displace older lithology, and none is observed to cut through a younger stratigraphy, which suggests that active faults have not ruptured the surface here. However, the strike and dip direction of the active faults that are mapped on the satellite images (Shah, 2015) match with the structural details of the faults that are mapped in the field (Figure 3). The structural details of the June 2015 and March 2018 earthquakes suggest that these quakes have occurred on $\sim \mathrm{NW}$ dipping fault plane (Figure 3) and not on $\sim \mathrm{SE}$ dipping fault plane (Figure 3C). The clear geomorphic evidence of the past fault rupture (Shah, 2015; Wang et al., 2017) indicates that the Kota Kinabalu pluton sits on the foot-wall portion of the fault (Figure 3B), which is the up-thrown block. The down-thrown block is on the SE portion of the region, and this configuration suggests that $\sim \mathrm{NW}$ dipping plane is the best possible fault plane solution for the above mentioned earthquakes. This further suggests that both of these quakes have either reactivated an older normal fault system or have occurred on a similar but new fault system. The proximity of the quakes closer to the existing fault system makes it more feasible to suggest that earthquakes have originated on the older fault system. The lack of evidence of recent fault ruptures associated with the co-seismic deformation of the earthquakes indicate that the quakes have occurred on a blind fault. And this seems consistent with the structural configuration of the older faults (Shah, 2015; Wang et al., 2017). The earthquakes have ruptured a portion of a large fault system that runs $\sim \mathrm{NE}-$ SW through the Borneo Island (Wang et al., 2017; Shah et al., 2018c). The occurrence of active normal faults in the region indicate $\sim \mathrm{NW}-\mathrm{SE}$ extension, which could be related to the tectonic stress associated with the regional oblique compression (Shah et al., 2018c). This interpretation argues that the region is slowly accumulating tectonic strain and can host medium to large magnitude earthquakes in the future. It will be further tested in future as more scientific investigations on Borneo become available. However, the earthquake hazard in the region cannot be ignored because evidence of active deformation is visible, and therefore people have to be updated on the available scientific wisdom (for more information, please go to section "Interaction With Locals About June 2015 Earthquake") about the region, and must be educated, trained, and equipped with the latest information on the earthquake hazards.

\section{Interaction With Locals About June 2015 Earthquake}

The post-June 2015 earthquake awareness related field session with locals in Ranau (Figure 4) suggests severe lack of earthquake science education in the region, and that is one of the major reasons why the earthquake took them by total surprise. People are still in shock, and some of them believe in myths and all of the unscientific information that was available. For example the Kadazan-Dusun community of people, which is the largest ethnic group in Sabah (Lasimbang, 2004; Halim et al., 2013), believe that the dead spirits settle at Mt. Kinabalu, which is regarded as a sacred place. The natives have performed "Monogit ceremony" or animal sacrifice over centuries to please the mountain god "Aki Nabalu" (Halim et al., 2013). Such rituals are performed annually to avoid any catastrophic event. The periodicity of such a ritual suggests that in the distant past damaging earthquakes might have occurred in the region. This needs a thorough investigation, and historical archival data can be useful resource to uncover such evidence.

Some of the people, who believe in myths, were not happy when on 30th May 2015 a group of 10 tourists stripped near Mt. Kinabalu. They believe that the God will be angry and will take revenge for such cultural insensitivity by some tourists. And unfortunately, just a week after this incident the infamous Mw 6 earthquake occurred in the region. Thus reinforcing their belief 

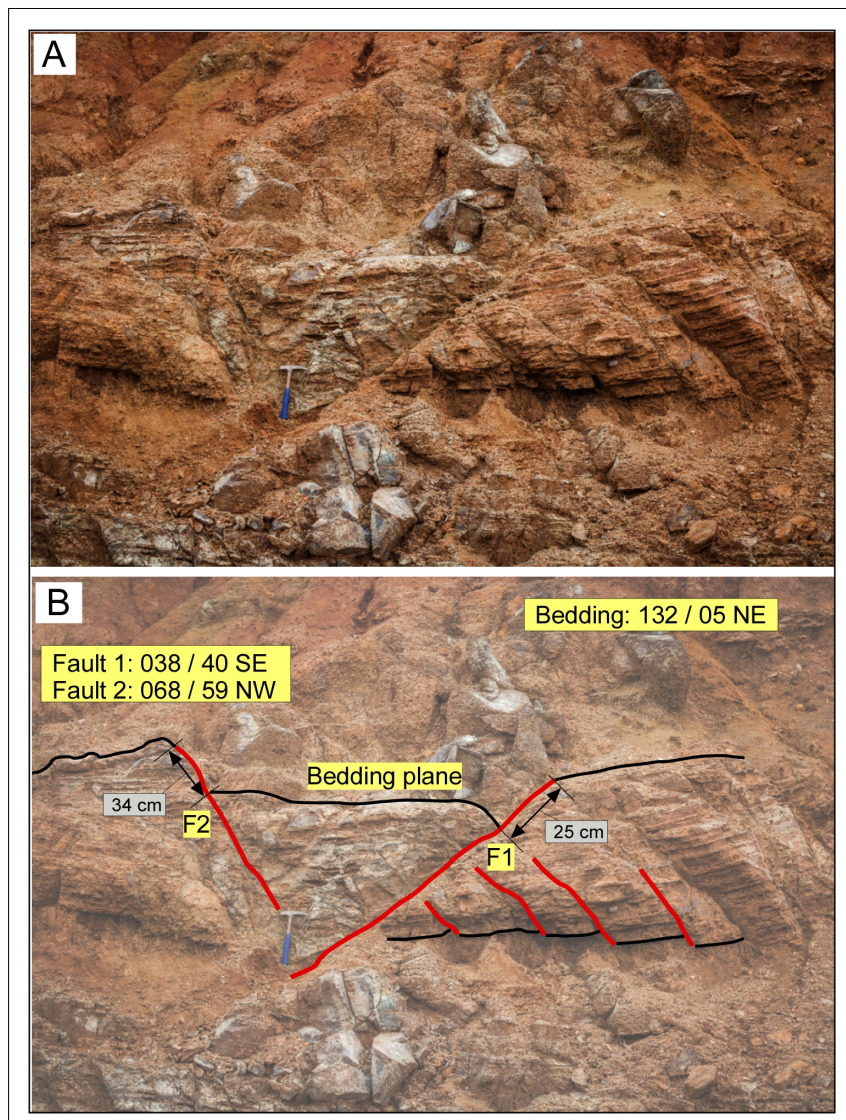

FIGURE 5 | The field photograph shows evidence of normal faulting in Ranau region, Sabah. The un-interpreted $(\mathbf{A})$ field photograph is interpreted below (B) and shows the rock sequence is cut through by the two prominent NW and SE dipping normal fault systems. The faults are older, and have not pierced through younger lithology.

in such super natural powers. A significant number of religious people also believe that this kind of obscenity by tourists led to the catastrophic event in Ranau, Sabah.

Several eyewitnesses' accounts have confirmed that the earthquake shaking lasted for $\sim 7 \mathrm{~s}$ and that the quake occurred between 6 and 7 a.m. The shaking was scary, and it was hard to understand what was happening, said the participants. The electricity and phone signals were disrupted, and subsequently restored in a few hours. Several cracks appeared on the ground (Figure 6), buildings, and roads but luckily no building collapsed due to earthquake or landslides in the region. Three students from Universiti Malaysia Sabah (UMS), Kota Kinabalu, claimed that the seismic shaking lasted for $\sim 10 \mathrm{~s}$ in Kota Kinabalu region. They were equally puzzled, surprised and were not aware that earthquakes can jolt this region as well. Their hostel was damaged, windows shattered, and the impact partially broke the swimming pool. A number of buildings at several places developed extensional cracks after the quake (Figure 3). Such structural damage must be repaired immediately to avoid any subsequent structural failure and damage in a future earthquake event.

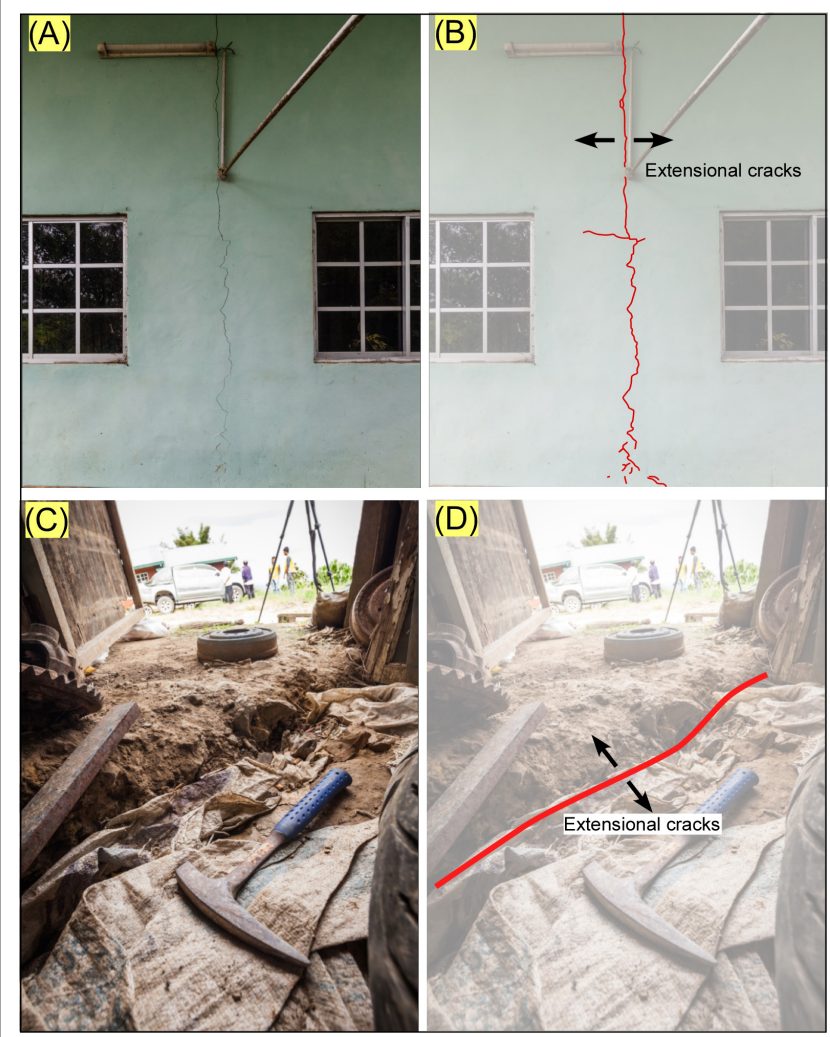

FIGURE 6 | The field photographs show evidence of co-seismic cracks that have developed during the June 2015 earthquake. The un-interpreted images are on the left $(\mathbf{A}, \mathbf{C})$ and interpreted images are on the right $(\mathbf{B}, \mathbf{D})$ of the observer.

Importantly, the curiosity of the people to know about the scientific background of the earthquake events in Sabah is a persistent quest for its inhabitants that we realized throughout our work in Sabah. Although, some people truly believe in various rituals, a large section of educated people are now asking pertinent questions about the science of the occurrence of earthquake in the region. We were told that the earthquake administration has installed seismic monitoring stations at various places in Sabah. This is a welcome initiative and could help in the understanding the crustal deformation in the region. Hopefully, more such stations will be installed throughout the country.

\section{Landslides Associated With June 2015 Earthquake}

The co-seismic effects in the forms of landslides have perhaps intensified in the recent past, and routinely some of the major earthquakes were reported to have caused co-seismic landslides. For example: the Mw 8.0 earthquake that struck Wenchuan region of China in 2008; the Mw 7.6 earthquake of Chi-Chi, Taiwan in 1999; the Mw 9.0 earthquake of 2011 in Tohoku, Japan, and the Mw 7.6 earthquake of Kashmir in 2005 (e.g., Wistuba et al., 2018). Similarly, extensive landslides were initiated just after the June 2015 earthquake that shattered the famous Mount 

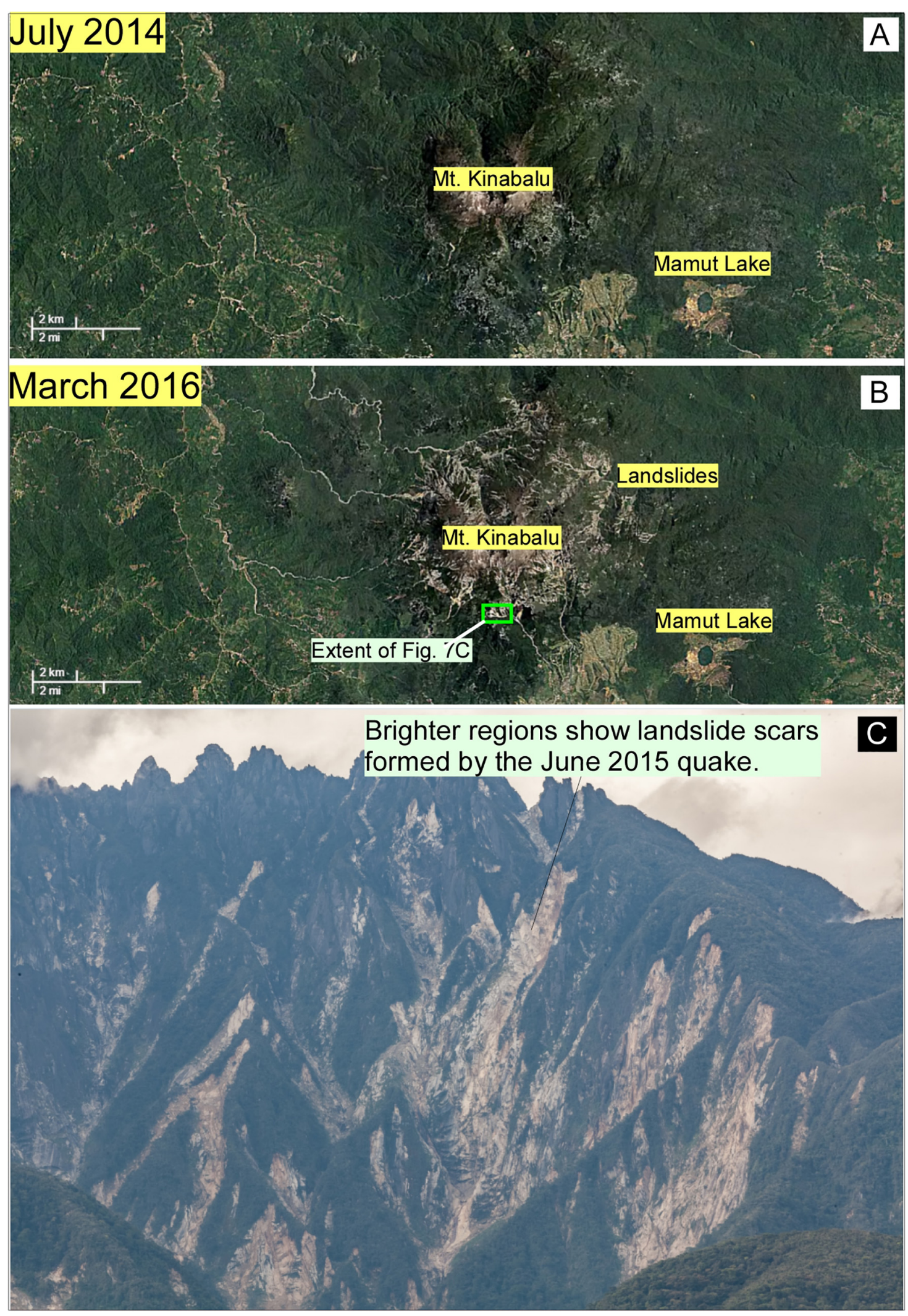

FIGURE 7 | Google satellite images show the Mount Kinabalu region before (A), and after the June 2015 earthquake (B). The extent of landslide occurrence on the steep slopes on the mountain is clearly visible. Field evidence of this is shown at the bottom (C). 
Kinabalu region, and this is said to be the main reason for the unfortunate loss of 18 hikers (Wang et al., 2017; Shah et al., 2018c). The Mount Kinabalu is a 4,100 m mountain of granitic composition that has formed in Late Miocene (Cottam et al., 2013). It is one of the highest mountain peaks in SE Asia, and therefore a favorite tourist attraction for hikers, which is why the earthquake caused considerable casualties. The satellite image captured before and after the landslide shows the widespread damage associated with co-seismic deformation (Figure 7). Most of the landslides occurred on the Mount Kinabalu, which could have occurred because of shaking of the hanging wall block (Figure 3B), as would be predicted normal faults that dip $\sim$ NW (Figure 3), and the presence of steep slopes could also contribute to it. The earthquake hypocentral depth ranges from $\sim 10$ to $13 \mathrm{~km}$, which has not been relocated, and therefore errors exist in both the depth and location of the recorded earthquake events. However, Wang et al. (2017) have relocated the main shock and eight aftershocks, which are distributed in a narrow zone of $\sim 15 \mathrm{~km} \times 5 \mathrm{~km}$, and are consistent with the previous mapped fault system (Shah, 2015). The coseismic slip of $<50 \mathrm{~cm}$ has occurred at a depth of 13-14 km (Wang et al., 2017), which is similar to the hypocenter depths that are used herein.

\section{Flooding After Landslides}

Earthquakes often cause landslides (Wistuba et al., 2018) and floods (Shah and Malik, 2017; Shah et al., 2018a), and this systemic chronological order of such disasters remains one of the most difficult tasks to accomplish, particularly during the post-disaster operations. Previous studies have demonstrated several such cases, for example a large number of landslides and associated floods were triggered by the Mw $7.6 \mathrm{Kashmir}$ earthquake that devastated the eastern portion of Pakistan and most of the Muzaffarabad area in 2005 (e.g., Kamp et al., 2008). Several eyewitness accounts suggest that a large quantity of debris associated with the 5th June 2015 landslide has accumulated in some of the rivers. This is notable in Liwagu River, which is located downslope of the Mount Kinabalu (Figures 4, 8). This is the reason why a large quantity of landslide derived debris has been accumulated in it. This caused choking of streams as sediment load builds up, which is particularly observed at bridges or narrow passages where flow of the material is restricted. Local reports also suggest that it rained for a few days after the earthquake, and since the Liwagu River was filled with debris therefore it caused floods with usual precipitation. A lot of residential areas, which are closer to the river (Figure 8) had to be evacuated. This opened up multiple disaster fronts, which are usually not expected.

This also confirms the recent works where the relation between the earthquakes, landslides, and floods is now fairly well established, and therefore to make most of what such disasters can entail one must work on strengthening of the scientific knowledge database, and sharing and coordination between various sectors (e.g., engineers, scientists, disaster management, etc.). Such efforts can greatly help in the overall reduction of the risk associated with a potential hazard that could become a future disaster.

\section{Artificial Lake, the Mamut Lake}

Locals informed us that they are worried about an artificial lake (Figures 4, 9) that formed from an abandoned mine known as Mamut Copper Mine (MCM), which is a porphyry type $\mathrm{Cu}$ $\mathrm{Au}$ deposit and it is related to quartz monzonite ("adamellite") that has formed from the upper Miocene Mount Kinabalu plutonism (Akira, 2000). The mine is located very close to the active fault system (Figure 4), and people are concerned that the situation may turn chaotic and disastrous if any future earthquake damaged the lake. Since the lake contains a large quantity of water therefore it can pose serious threat to people living in the downstream direction. This mine also poses a threat to the pristine environment of tropical rainforests because it produces a large volume of sulfidic mineral waste (van der Ent and Edraki, 2018), which is often mobilized by the high amount of precipitation in the tropics of Sabah. The polluted mine pit derived with water often percolates into the fresh river and groundwater reserves. Therefore, the lake poses a great risk to life and environment, and ought to be properly managed.

\section{Short Documentary Movie}

The interview session with victims of the Sabah Earthquake of June 2015, and the various interactions with locals during our field exercises in Malaysia and Brunei inspired us to make a short movie on the science of earthquake disasters in Borneo. The movie is less than $10 \mathrm{~min}$ and blends the science of earthquakes in NW Borneo with the real stories of locals who were affected by the earthquake. It is freely available on YouTube and can be accessed here: https://www.youtube.com/watch?v= BtgsgTLI8Ck.

The interaction and interview session was an eye opener as it clearly shows that people are not aware about the earthquake hazards in the region, and are equally not aware about the existence of regional seismogenic fault systems. This information is vital for any future planning of science education in the region, and particularly about earthquake hazards. The movie shows the current scientific discourse on the understanding of the earthquake geology of the region, which is mainly the contributions from the second author of this paper. It presented a very brief snapshot of what type of earthquakes occur in NW Borneo, and what it means on the tectonic scale. The local interviews are placed in the context to make the documentary impactful, and scientifically sound. The movie highlights how scientists gather evidence about active faults through the study of satellite imagery, and how that information is used to target field sites where the usage of various instruments is required to study details about faults, etc. Therefore, the documentary movie is made with an underlying motivation to improve the scientific knowledge about earthquake hazards in SE Asia, and particularly in Sabah. It highlights the need for making scientifically sound documentary movies on earthquake science and how such efforts can help us in dissemination of authentic scientific information to public, students, and others. This simple effort demonstrates that a scientific documentary movie can translate a geologically difficult and complicated region into a simple and meaningful cinema, which can be 


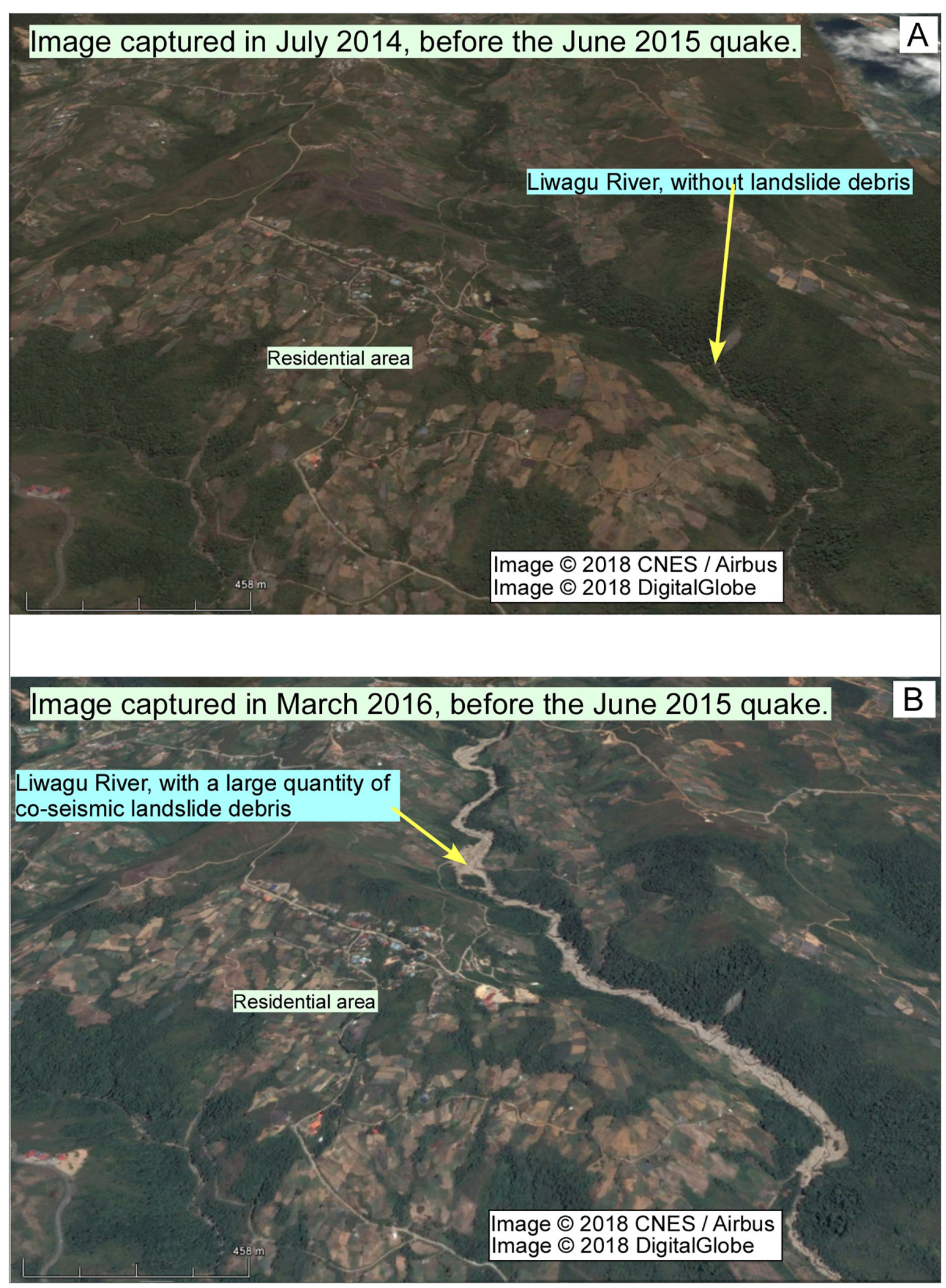

FIGURE 8 | Google satellite images show the scenes captured before (A) and after (B) the June 2015 quake in Sabah. The changes in Liwagu River are highlighted. The filling on the river bed are the remains of the debris that was derived from the earthquake induced landslides in the Mt. Kinabalu region. The debris filled river makes it vulnerable to future fluvial flooding. 


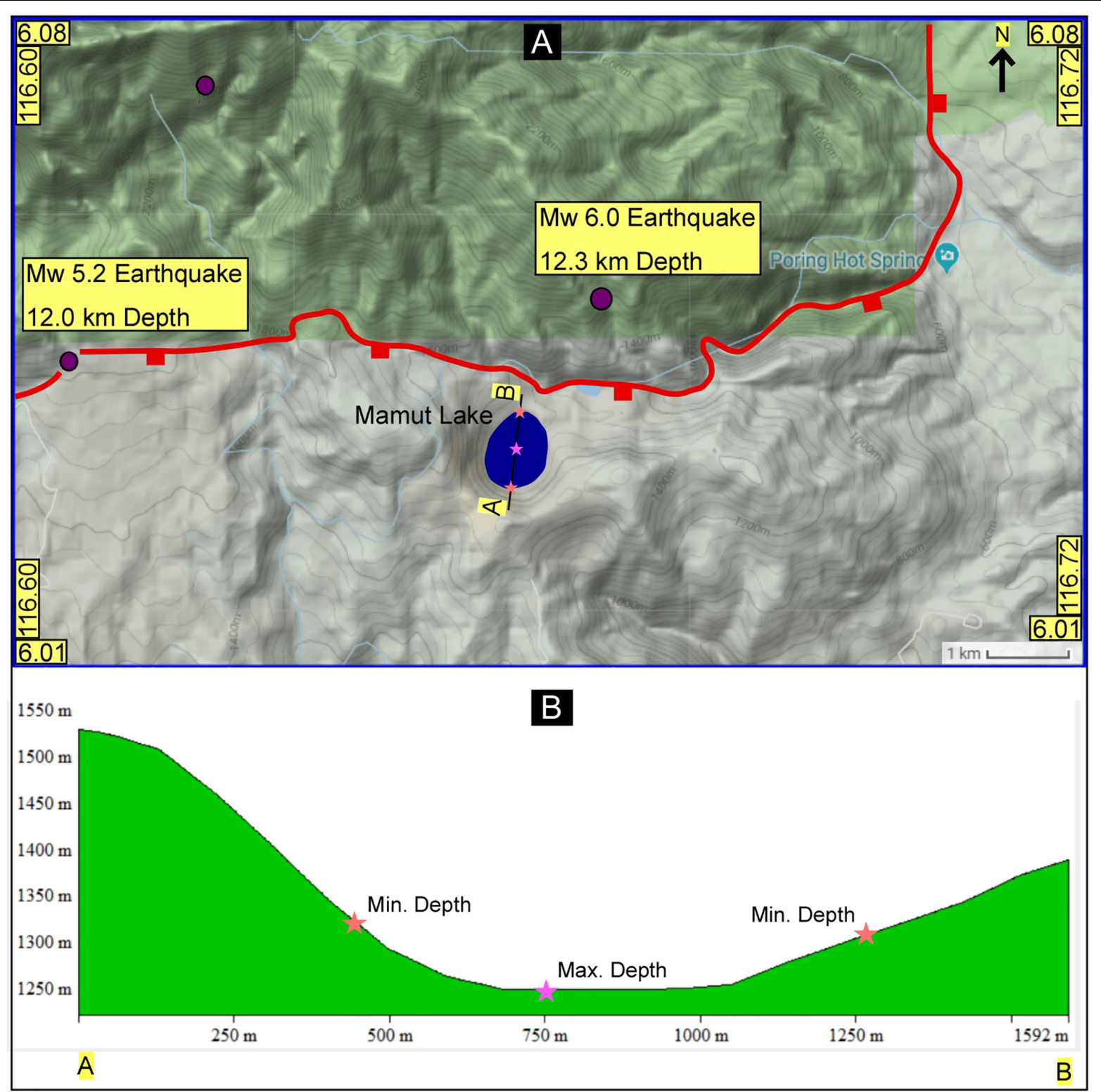

FIGURE 9 | Location and topographic map of the Mamut Lake in Ranau, which is an abandoned mine pit, and poses environmental and flood hazards. The topographic profile across the mine pit is shown in panels $\mathbf{( A , B )}$.

understood by ordinary people. However, such efforts can become more meaningful if more members of the scientific community get involved in such endeavors. Special grants are required to support such efforts and the scientists working on outreach programs.

\section{DISCUSSION}

\section{Why Earthquake Science Education Is Important in SE Asia}

A major earthquake of $\mathrm{Mw} 7.5$ struck Minahasa, Sulawesi, Indonesia on 28th September 2018 and it also caused the formation of tsunami waves, which could quickly reach the coastal regions. The tsunami is reported to have occurred because of the collapse of a volcano. The earthquake shaking together with the deadly tsunami waves resulted in extensive damage to life and property with a loss of more than 2,000 lives. Importantly, the earthquake ruptured a previously mapped active left-lateral strike-slip fault system, the Palu-Koro fault (Figure 2B), at a shallower depth of $10.0 \mathrm{~km}$ (Hui et al., 2018; Sassa and Takagawa, 2018). The unfortunate loss of life and property is mainly related to tsunami, liquefaction, and earthquake shaking, which clearly suggests that poor infrastructure and lack of earthquake disaster preparedness are the unpleasant realities that continue to challenge us. This has happened in a region which is well 
known for being one of the most tectonically active regions in Asia (e.g., Indonesia and the Philippines). Although the previous geological wisdom has exclusively demonstrated that a number of major active fault systems that encircle South and Southeast Asia (e.g., Sunda Megathrust) are capable of producing some of the most destructive earthquakes (e.g. Bilham, 2019) on the planet (Figure 2) yet our efforts are not making any decent progress on ground. This is a major challenge that stares us in our face, and we must take it head-on. Loss of life on known active fault zones is avoidable provided we work toward the solution.

Similarly, the nature and extent of destruction caused by the past earthquakes on the Sunda megathrust fault offers more lessons of wisdom (Shearer and Bürgmann, 2010; Shah et al., 2018b). It marks the location of the Sumatra subduction zone along which the Indo-Australia oceanic plate subducts under Sunda plate (Sieh, 2007; Shearer and Bürgmann, 2010), and this shall continue to pose major risk to millions of people (Figure 2). In December 2004 a portion of the fault broke, and caused one of the most devastating earthquakes in the region, which was followed by an equally devastating tsunami. Both these disasters resulted in the unfortunate loss of $\sim 156,000$ to 178,000 people across more than 11 nations (Liu et al., 2005; Geist et al., 2006; Shah et al., 2018b). Such enormous scale of devastation happened even after spending billions of dollars on understanding the causes of earthquakes since the inception of the earthquake sciences, which started more than 250 years ago. This clearly suggests that progress that is needed to secure life has not been achieved yet, and one of the major causes of such failure is the wide gulf between science its applicability on ground (Shah et al., 2018b). The earthquake studies in SE Asia have grown since the 2004 Indian Ocean earthquake event, and great efforts have been made in understanding the causes of earthquakes in the region. The newly compiled regional probabilistic seismic hazard map of SE Asia (Chan et al., 2017) is one such example where reliable seismic hazard maps are produced with a motivation to save life and property. Although this map is not complete, yet it highlights the major seismogenic sources in the region. It highlights areas with high seismic risk, and these are usually associated with high slip rates on major fault systems in the region (Figure 2). However, our understanding of faulting suggests that low slipping faults can also pose significant damage, as witnessed during the recent medium magnitude earthquake that occurred on a normal fault in Sabah (Malaysia) on 5th June and caused unfortunate loss of 18 people (Wang et al., 2017; Shah et al., 2018c). It is important therefore to know the sources of earthquake occurrences in the region and to map and understand the extent of seismic risk.

Further, our knowledge about the science of earthquakes has grown manifold throughout the historical past, and now we are at a stage where we do understand to a large extent the various causes of faulting. However, we are still unable to predict the exact timing of earthquake events, and that is the reason why earthquake forecasting is now more popular in scientific community (Hough, 2010). This also means that we have to put in more efforts in place to educate public about the potential of earthquake disasters, and how to live with one (Shah, 2014). This is particularly important in places that are highly prone to earthquake risk, and SE Asia is one such example where serious scientific awareness campaign is highly required to educate public about the science and remedy of earthquake disasters (Shah et al., 2018b). This is significant because a large number of people live on or close to active faults, and are at a greater risk (Figure 2). Generally, earthquake related education material is distributed in communities to help them understand the science of faulting, what to do when an earthquake strikes, and how to live with them (Sieh, 2007; Cummins, 2017). Here, we extend this approach by educating public through the use of documentary movies, which can be made freely available to benefit large number of people globally.

Our field session with students and public at large in Borneo clearly suggests lack of awareness about the science of earthquake hazards in the region. Throughout our project (which is ongoing) on the science of earthquakes in NW Borneo we realized that earthquake related education is needed and such efforts will make a major difference in changing the attitude of people toward earthquake hazards. Since Borneo was not in the radar of seismic resilient building planners therefore infrastructure to withstand earthquake shaking has not been planned in the past (Shah et al., 2018b). The first step toward making of an earthquake hazard and risk resilient society is to produce reliable fault mapping data (Chan et al., 2017; Shah et al., 2018b) that can be used to educate authorities about the level of risk, and what to build, how and where. Such information is largely absent in Borneo, although, some progress has been made recently about the science of earthquake and outreach activities (Shah, 2015; Mathew et al., 2016a,b; Tongkul, 2017; Wang et al., 2017; Shah et al., 2018b).

\section{Earthquake Science Education Program: Role of Scientists}

Earthquake science has grown in various directions from microscopic to megascopic levels (details in Shah et al., 2018b), however, we are still unable to save life because the prediction has not gone far, and a large portion of the population still lacks education and infrastructure to deal with such hazards (Shah et al., 2018a,b). People look forward to hearing from the scientists about the science of earthquake disasters but unfortunately not many local or international experts have participated in any such interactive sessions with locals. One of the major reasons for this is the lack of funding, which hinders any such program and progress. Therefore, it is required to allocate a portion of annual scientific budget for earthquake science education, outreach, and awareness exercises. All efforts should be made to make such programs more meaningful, successful and rewarding. Scientists should be motivated to participate in such programs through incentives, rewards, and other similar encouragements. Educating people about hazards will help in removing the ambiguity related to false reporting, propaganda, and exaggerated exigencies surrounding science, and in particular earthquakes (Brumbaugh, 1999; Paton et al., 2010). 


\section{Earthquake Science in School Curriculum}

Scientific education has progressed greatly with time but awareness around it has not been able to match it. A cursory look at it reinforces that the scientific community has mainly remained focused in progression of science but not on how science can be transposed into action on ground. The huge void that exists is now being filled with unscientific discourse and has reinforced the old belief system of going away from the scientific wisdom. This also comes from schools where teachers are not well equipped to teach students about science and the latest critical developments in sciences, therefore such education system will not be useful or engaging for students. This is one of the foremost reasons why many students do not continue in science (Holton, 1992). The answer to this is to fully train teachers first so they can disseminate updated, authentic, and rigorously researched science to students from a very early stage. The existing school curriculum must be thoroughly reviewed with the help of local and international science experts, and accordingly upgraded to the scale of latest developments. The local scientific community can enormously help any nation to accomplish this goal by coordinating with schools and other institutions. It is an important step toward the development of a scientifically aware and responsible society.

\section{Training Adults and Children}

Global data on disasters suggest that children are more vulnerable and account for about $30-50 \%$ of deaths (Wistuba et al., 2018). They require protection from adults, but even this may change little on ground because most of the casualties occur because of lack of training, education and skills to protect one self and to be protected during a disaster (Mitchell et al., 2008; Haynes and Tanner, 2015; Amri et al., 2018). It makes it imperative for children and youth to play an active and important role in disaster risk reduction programs, and this has been recognized in the global commitment for disaster risk reduction, the Sendai Framework for Disaster Risk Reduction 2015-2030 (UNISDR 2015). This can be achieved if proper scientific and administrative framework is established to educate, train, and equip the younger generations with the skills they need to understand hazards and the associated risk, and how to fight a disaster. Children are often curious to know and learn new things and a good grooming can greatly improve their skills, which can dramatically change our perception about how young minds can actively contribute toward the reduction of disaster related casualties (Tom et al., 2008). Adults who have traditionally taken a leading role in various disaster risk reduction activities need to realize that it is time to fully prepare the younger generations to work with adults. The culture of living with disasters has to be internalized, accepted and acted upon. The adults have a special role to play in this exercise because they are experienced, and can significantly improve the standard of such activities world over.

\section{Religion and Earthquake Hazards}

There are many myths surrounding earthquake disasters. One such widely held myth is that earthquakes are evidence of God's wrath against people who have disobeyed (Marianna et al., 2016). When Sabah earthquake occurred a number of newspapers also reported similar stories. The religious and cultural view on the occurrence of natural disasters has thrived throughout the history as people wanted to know more about the unexplainable and destructive face of the Earth. Such views have consolidated around different myths because of lack of scientific explanation for the same. The logical explanation that might help is to ask people if God is testing you through disasters, how about disease or ailments? Why one has to visit a doctor to cure a disease, if that is also a test from God. The earthquake hazards demand a cure not a mythological unreasoning. This can be effectively achieved by working with religious leaders and various other community helpers to equip and train them about the science of disasters and how to live with them. It is equally important to understand that earthquakes have thrived on the planet Earth before the emergence of humans! Faults are much older than any of the known human remains or civilizations.

\section{Documentary Movies on the Major Fault Systems in South and Southeast Asia}

Field interaction with locals in Borneo clearly suggests that people are aware about the whereabouts of the San Andreas Fault, a major dextral strike-slip fault system (Forand et al., 2018) in United States but they do not know about the existence of similar fault systems in their neighborhood in South and Southeast Asia (e.g., Sunda Megathrust) (Shah et al., 2018b). This is a challenge that requires attention and an action oriented strategic planning on ground. And one of the best possible solutions will be to make scientifically realistic educational documentary movies on the major fault systems. Figure 2 shows such fault systems in South and Southeast Asia, which include the Chaman fault, the Main Himalayan/Frontal thrust, the Sagaing fault, the Sunda megathrust fault, the Sumatran fault, and the Sorong fault. Such efforts will definitely improve our relationship with the landscape, faulting, earthquakes, and how to live in harmony with earthquake hazards. This has perhaps never been as important in the historical past as it is today because of the urbanization, and population growth that has exploded post-industrial periods. Therefore, it is our duty, as responsible scientists, to train, educate and inform people that seismogenic faults are here to stay and there is no existing technique or technology to stop faults from slipping, which makes living with such hazards a reality.

\section{CONCLUSION}

This paper briefly touches on a string of topics that are important to win the centuries old battle with earthquake hazards. Such concerns demand much detailed explanation, which is beyond the scale of this work. And the biggest challenge in achieving all of the above is to build a strategy around the most useful process on how to stop hazards from becoming disasters. This is particularly important for earthquake hazards, which pose consistent threat to most of the world inhabitants who live in the vicinity of active fault systems. South and Southeast Asia is home to some of major active faults (e.g., Sunda megathrust) 
on Earth, and the possibility of major earthquakes on these fault systems is unavoidable, and therefore there is a great concern for the loss of life and property. Since earthquakes are unpredictable it means that we have to work on equipping people to be prepared for any such eventuality. One of the first steps to achieve this is to educate, train, and engage local communities that live on or near active faults. Faults have structured the brittle parts of the planet on which we live and build our homes, and remember there is no mechanism to stop fractures from becoming faults. This means we must learn how to live with faults, and that we can do so by earthquake education and awareness, and sharing of such information with family, friends, and colleagues. In the present times, most of the people use gadgets to learn and communicate. This medium can be a highly useful platform for the dissemination of earthquake science education and at a much larger scale. Another useful tool is to make documentary movies on the science of disasters. Perhaps the only talk available on YouTube on earthquakes that has attained some viewership is by Prof. Ross Stein, who is a well-known geophysicist with the United States Geological Survey in California. It can be viewed here: https://www.youtube. com/watch? $\mathrm{v}=\mathrm{Bg} 4 \mathrm{kSIgn} 67 \mathrm{I}$. The total views are $\sim 43 \mathrm{k}$ (accessed on 31st January 2019) and when it is compared with the normal viewership of songs from any famous artist it becomes evident that science is not what attracts people! However, the good news is that a number of universities are making scientific talks freely available on the net. Many scientists are also making effort to reach out to people with the most authentic information, but these efforts could be made mainstream by making serious cinema that entertains people via science. The small step (shown above) of making an earthquake documentary movie on Sabah demonstrates that it is possible and doable, but a strong workforce is needed to make science easily available to people. The documentary intends to motivate scientists to get involved with such documentary projects with a mission to reduce the propagation and consumption of adulterated scientific

\section{REFERENCES}

Akira, I. (2000). Genesis of the Mamut porphyry copper deposit, Sabah, East Malaysia. Resour. Geol. 50, 1-23. doi: 10.1111/j.1751-3928.2000.tb00052.x

Amri, A., Haynes, K., Bird, D. K., and Ronan, K. (2018). Bridging the divide between studies on disaster risk reduction education and child-centered disaster risk reduction: a critical review. Childrens Geogr. 16, 239-251. doi: 10.1080/ 14733285.2017.1358448

Balaguru, A., Nichols, G., and Hall, R. (2003). The origin of the 'circular basins' of Sabah, Malaysia. Geol. Soc. Malaysia 46, 335-351.

Balendra, T., and Li, Z. (2008). Seismic hazard of Singapore and Malaysia. Electron. J. Struct. Eng. 8, 57-63.

Barnett, M., Wagner, H., Gatling, A., Anderson, J., Houle, M., and Kafka, A. (2006). The impact of science fiction film on student understanding of science. J. Sci. Educ. Technol. 15, 179-191. doi: 10.1007/s10956-006-9001-y

Bilham, R., (2019). Himalayan Earthquakes: A Review of Historical Seismicity and Early 21st Century Slip Potential. London: Geological Society of London, 483.

Bondár, I., Stephen, C. M., Robert, E., and Eric, A. B. (2004). Epicentre accuracy based on seismic network criteria. Geophys. J. Int. 156, 483-496. doi: 10.1111/j. 1365-246X.2004.02070.x

Bondár, L., and McLaughlin, K. (2009). A new ground truth data set for seismic studies. Seismol. Res. Lett. 80, 465-472. doi: 10.1785/gssrl.80.3.465

Brumbaugh, D. S. (1999). Earthquakes: Science and Society. New Jersey: Prentice Hall. information that is routinely fed to public. The target is to reach out to the unprepared populations in Asia and elsewhere who live in earthquake hazard zones and to help them to become an earthquake resilient community.

\section{ETHICS STATEMENT}

Curtin Sarawak Ethical Committee has kindly granted the permission to conduct fieldwork in Sabah. Before the formal interviews of the subjects were recorded a prior written informed consent was signed by each participant.

\section{AUTHOR CONTRIBUTIONS}

$\mathrm{BN}$ and AS coordinated the work and planned the outline of the manuscript. BN mainly contributed in the collection of field data, figures, and writing. AS conceptualized the paper and contributed in writing of the manuscript. MP managed the field related activities, contributed in the methodology, and results sections.

\section{FUNDING}

This work was funded by the National Geographic Society, United States.

\section{ACKNOWLEDGMENTS}

The authors are very grateful to all the people who helped us in data collection in Sabah. Special thanks to Dr. Sheeba Khwaja for her work on English corrections. Financial support from the National Geographic Society is highly appreciated. Without their support fieldwork would have been impossible.

Chan, C., Wang, Y., Shi, X., Ornthammarath, T., Warnitchai, P., Kosuwan, S., et al. (2017). Toward Uniform Probabilistic Seismic Hazard Assessments For Southeast Asia. Washington, DC: American Geophysical Union.

Cottam, M. A., Hall, R., Sperber, C., Kohn, B. P., Forster, M. A., and Batt, G. E. (2013). Neogene rock uplift and erosion in northern Borneo: evidence from the Kinabalu granite, Mount Kinabalu. J. Geol. Soc. 170, 805-816. doi: 10.1144/ jgs2011-130

Cullen, A. (2010). Transverse segmentation of the Baram - Balabac Basin, NW Borneo: refining the model of Borneo's tectonic evolution. Petrol. Geosci. 16, 3-19. doi: 10.1144/1354-079309-828

Cummins, P. R. (2017). Geohazards in Indonesia: earth science for disaster risk reduction-introduction. Geol. Soc. 441, 1-7. doi: 10.1144/SP441.11

DeBoer, G. E. (2000). Scientific literacy: another look at its historical and contemporary meanings and its relationship to science education reform. J. Res. Sci. Teach. 37, 582-601. doi: 10.1002/1098-2736(200008)37:6<582::AIDTEA5>3.0.CO;2-L

Forand, D., Evans, J. P., Janecke, S. U., and Jacobs, J. (2018). Insights into fault processes and the geometry of the San Andreas fault system: analysis of core from the deep drill hole at Cajon Pass, California. Geol. Soc. Am. Bull. 130, 64-92. doi: 10.1130/B31681.1

Frank, S. (2003). Reel reality: science consultants in hollywood. Sci. Cult. 12, 427-443. doi: 10.1080/0950543032000150319

Geist, E. L., Titov, V. V., and Synolakis, C. E. (2006). Tsunami: wave of change. Sci. Am. 294, 56-63. doi: 10.1038/scientificamerican0106-56 
Halim, A. A., Jawan, J. A., Ismail, S. R., Othman, N., and Masnin, M. H. (2013). Traditional knowledge and environmental conservation among indigenous people in Ranau, Sabah. Glob. J. Hum. Soc. Sci. Geogr. Geo Sci. Environ. Disaster Manag. 13, 5-12.

Hall, R. (2002). Cenozoic geological and plate tectonic evolution of SE Asia and the SW Pacific: computer-based reconstructions, model and animations. J. Asian Earth Sci. 20, 353-431. doi: 10.1016/S1367-9120(01)00069-4

Hall, R., van Hattum, M. W., and Spakman, W. (2008). Impact of India-Asia collision on SE Asia: the record in Borneo. Tectonophysics 451, 366-389. doi: $10.1016 /$ j.tecto.2007.11.058

Haynes, K., and Tanner, T. (2015). Empowering Young People and strengthening resilience: youthcentred participatory video as a tool for climate change adaptation and disaster risk reduction. Childrens Geogr. 13, 357-371. doi: 10. 1080/14733285.2013.848599

Hesse, S., Back, S., and Franke, D. (2009). The deep-water fold-and-thrust belt offshore NW Borneo: gravity-driven versus basement-driven shortening. Geol. Soc. Am. Bull. 121, 939-953. doi: 10.1130/B26411.1

Holton, G. (1992). How to think about the 'anti-science' phenomenon. Public Underst. Sci. 1, 103-128. doi: 10.1088/0963-6625/1/1/012

Hough, S. E. (2010). Predicting the Unpredictable: The Tumultuous Science of Earthquake Prediction. Princeton, NJ: Princeton University Press, 272. doi: 10.1515/9781400883547

Hui, G., Li, S., Wang, P., Suo, Y., Wang, Q., and Somerville, I. D. (2018). Linkage between reactivation of the sinistral strike - slip faults and 28 September 2018 Mw 7.5 Palu Earthquake, Indonesia. Sci. Bull. 64, 26-35. doi: 10.1016/j.scib. 2018.11.021

Kamp, U., Growley, B. J., Khattak, G. A., and Owen, L. A. (2008). GIS-based landslide susceptibility mapping for the 2005 Kashmir earthquake region. Geomorphology 101, 631-642. doi: 10.1016/j.geomorph.2008.03.003

King, R. C., Backe, G., Morley, C. K., Hillis, R. R., and Tingay, M. R. P. (2010a). Balancing deformation in NW Borneo: quantifying plate-scale vs. gravitational tectonics in a delta and deepwater fold-thrust belt system. Mar. Petrol. Geol. 27, 238-249. doi: 10.1016/j.marpetgeo.2009.07.008

King, R. C., Hillis, R. R., Tingay, M. R. P., and Damit, A. R. (2010b). Present day stress and neotectonic provinces of the Baram Delta and deep-water fold-thrust belt. J. Geol. Soc. 166, 197-200. doi: 10.1144/0016-76492008-062R

Lam, N., Tsang, H. H., Looi, D., Lumantarna, E., and Wilson, J. (2016). "Seismic hazard modelling for Malaysia," in Proceeding of the Australian Earthquake Engineering Society 2016 Conference, Melbourne, VIC, 1-12.

Lasimbang, R. (2004). To promote the kadazandusun languages of Sabah. Austr. Bus. Deans 34, 10-12.

Liu, P. L. F., Lynett, P., Fernando, H., Jaffe, B. E., Fritz, H., Higman, B., et al. (2005). Observations by the international tsunami survey team in Sri Lanka. Science 308, 1595-1595. doi: 10.1126/science. 1110730

Loi, D. W., Raghunandan, M. E., and Swamy, V. (2018). Revisiting seismic hazard assessment for peninsular malaysia using deterministic and probabilistic approaches. Nat. Hazards Earth Syst. Sci. 18, 2387-2408. doi: 10.5194/nhess-182387-2018

Marianna, B., Francesco, D., and Roberto, G. (2016). Earthquakes, religion, and transition to self-government in Italian cities. Q. J. Econ. 131, 1875-1926. doi: 10.1093/qje/qjw020

Mathew, M. J., Menier, D., Siddiqui, N., Kumar, S. G., and Authemayou, C. (2016a). Active tectonic deformation along rejuvenated faults in tropical Borneo: inferences obtained from tectono-geomorphic evaluation. Geomorphology 267, 1-15. doi: 10.1016/j.geomorph.2016.05.016

Mathew, M. J., Menier, D., Siddiqui, N., Ramkumar, M., Santosh, M., Kumar, S., et al. (2016b). Drainage basin and topographic analysis of a tropical landscape: insights intosurface and tectonic processes in northern Borneo. J. Asian Earth Sci. 124, 14-27. doi: 10.1016/j.jseaes.2016.04.016

Menier, D., Mathew, M., Pubellier, M., Sapin, F., Delcaillau, B., Siddiqui, N., et al. (2017). Landscape response to progressive tectonic and climatic forcing in NW Borneo: implications for geological and geomorphic controls on flood hazard. Sci. Rep. 7:457. doi: 10.1038/s41598-017-00620-y

Mitchell, T., Haynes, K., Hall, N., Choong, W., and Oven, K. (2008). The roles of children and youth in communicating disaster risk. Child. Youth Environ. 18, 254-279.

Morley, C. K. (2009). Growth of folds in deep-water setting. Geopshere 5, 59-89. doi: $10.1130 /$ GES00186.1
National Science Foundation (2000). Indicators: Science and Engineering 2000. Washington, DC: National Science Foundation.

Paton, D., Bajek, R., Okada, N., and McIvor, D. (2010). Predicting community earthquake preparedness: a cross-cultural comparison of Japan and New Zealand. Nat. Hazards 54, 765-781. doi: 10.1007/s11069-010-9500-2

Sandal, S. T. (1996). The Geology and Hydrocarbon Resources of Negara Brunei Darussalam. Petaling: Syabas.

Sapin, F., Hermawan, I., Pubellier, M., Vigny, C., and Ringenbach, J. C. (2013). The recent convergence on the NW Borneo Wedge-a crustal-scale gravity gliding evidenced from GPS. Geophys. J. Int. 2, 549-556. doi: 10.1093/gji/ggt054

Sapin, F., Pubellier, M., Lahfid, A., Janots, D., Aubourg, C., and Ringenbach, J. C. (2011). Onshore record of the subduction of a crustal salient: example of the NW Borneo Wedge. Terra Nova 23, 232-240. doi: 10.1111/j.1365-3121.2011. 01004.x

Sassa, S., and Takagawa, T. (2018). Liquefied gravity flow - induced tsunami: first evidence and comparison from the 2018 Indonesia Sulawesi earthquake and tsunami disasters. Landslides 16, 195-200. doi: 10.1007/s10346-018-1114-x

Shah, A. A. (2013). Megathrust earthquakes and the associated volcanic subsidence. Curr. Sci. 105, 567-567.

Shah, A. A. (2014). "Book review," in Predicting the Unpredictable: The Tumultuous Science of Earthquake Prediction, Vol. 18, ed. S. Hough (Princeton, NJ: Princeton University Press), 373-374.

Shah, A. A. (2015). Understanding the recent Sabah Earthquake, and other seismogenic sources in North West Borneo. Sci. Malaysia 11, 7-10.

Shah, A. A., and Malik, J. N. (2017). Four major unknown active faults identified, using satellite data, in India and Pakistan portions of NW Himalaya. Nat. Hazards 88, 1845-1865. doi: 10.1007/s11069-017-2949-5

Shah, A. A., Khwaja, S., Shah, B. A., Reduan, Q., and Jawi, Z. (2018a). Living with earthquake and flood hazards in Jammu and Kashmir, NW Himalaya. Front. Earth Sci. 6, 179. doi: 10.3389/feart.2018.00179

Shah, A. A., Qadri, T., and Khwaja, S. (2018b). Living with earthquake hazards in South and Southeast Asia. ASEAN J. Commun. Engag. 2, 15-37. doi: 10.7454/ ajce.v2i1.105

Shah, A. A., Zhafri, M. N., Delson, J., and Navakanesh, B. (2018c). Major strikeslip faults identified using satellite data in central Borneo, SE Asia. Geosciences 8:156. doi: $10.3390 /$ geosciences 8050156

Shearer, P., and Bürgmann, R. (2010). Lessons learned from the 2004 SumatraAndaman megathrust rupture. Annu. Rev. Earth Planet. Sci. 38, 103-131. doi: 10.1146/annurev-earth-040809-152537

Sieh, K. (2007). The Sunda megathrust-past, present and future. J. Earthquake Tsunami 1, 1-19. doi: 10.1142/S179343110700002X

Tom, M., Haynes, K., Hall, N., Choong, W., and Oven, K. (2008). The roles of children and youth in communicating disaster risk. Children Youth Environ. 18, 254-279. doi: 10.1007/s11920-018-0942-7

Tongkul, F. (2017). Active tectonics in Sabah - seismicity and active faults. Bull. Geol. Soc. Malaysia 64, 27-36. doi: 10.7186/bgsm64201703

van der Ent, A., and Edraki, M. (2018). Environmental geochemistry of the abandoned Mamut Copper Mine (Sabah) Malaysia. Environ. Geochem. Health 40, 189-207. doi: 10.1007/s10653-016-9892-3

Wang, Y., Wei, S., Wang, X., Lindsey, E. O., Tongkul, F., Tapponnier, P., et al. (2017). The $2015 \mathrm{M}$ w $6.0 \mathrm{Mt}$. Kinabalu earthquake: an infrequent fault rupture within the Crocker fault system of East Malaysia. Geosci. Lett. 4:6. doi: 10.1186/ s40562-017-0072-9

Wistuba, M., Malik, I., Krzemień, K., Gorczyca, E., Sobucki, M., WrońskaWałach, D., et al. (2018). Can low-magnitude earthquakes act as a triggering factor for landslide activity? Examples from the Western Carpathian Mts, Poland. CATENA 171, 359-375. doi: 10.1016/j.catena.2018.07.028

Conflict of Interest Statement: The authors declare that the research was conducted in the absence of any commercial or financial relationships that could be construed as a potential conflict of interest.

Copyright (c) 2019 Navakanesh, Shah and Prasanna. This is an open-access article distributed under the terms of the Creative Commons Attribution License (CC BY). The use, distribution or reproduction in other forums is permitted, provided the original author(s) and the copyright owner(s) are credited and that the original publication in this journal is cited, in accordance with accepted academic practice. No use, distribution or reproduction is permitted which does not comply with these terms. 